\title{
Gênero, docência e cadernos de receita na caçarola da cultura visual
}

Juzelia de Moraes Silveira ${ }^{1}$

\section{Resumo}

O presente artigo, oriundo de reflexões iniciais da pesquisa doutoral desenvolvida no Programa de Pós Graduação em Arte e Cultura Visual/FAV/UFG, visa discorrer sobre a possibilidade investigativa de questões referentes à subjetividade dos sujeitos, isto por meio de temas pertencentes à esfera do cotidiano e o modo como estas se articulam com a prática docente. Para tanto, utiliza-se o caderno de receitas culinárias como objeto desta análise, buscando pensar sobre e como os elementos presentes em seu interior não constituído apenas por receitas, mas por recortes de ordens variadas - e a atenção sobre o seu modo de construção em meio ao contexto sociocultural específico, podem provocar observações a respeito das relações de gênero. Diante da perspectiva da cultura visual e dos estudos do cotidiano, busca-se pensar por meio da investigação deste objeto e dos diálogos suscitados em relação ao tema gênero, como tais questões podem vir a influenciar a prática docente.

Palavras-chave: cadernos de receita culinária; gênero; prática docente.

\section{Abstract}

This article, originally from initial thoughts of doctoral research developed in the Graduate Program in Art na Visual Culture/FAV/UFG, aims to discuss the investigative possibilities regarding the subjectivity of the subjects, by means of themes pertaining to the realm of everyday life and how they articulate with the teaching practice. To do so, is used a cookbook as the object of this analysis, seeking to think how the elements present in it - not only constituted by recipes, but by various others clippings - and the attention to its specific way of construction in the middle of the socio-cultural context, may cause observations about gender relations. Faced with the prospect of visual culture and everyday studies, this article proposed to think through the investigation of this object and dialogues raised in relation to gender issues, how such matters end up influencing the teaching practices.

Keywords: cookbook; gender; teaching practice.

\section{O início da cozedura de ingredientes subjetivos}

Uma das principais mudanças no âmbito das pesquisas científicas sob a perspectiva dos Estudos da Cultura Visual diz respeito à inclusão de aspectos por muito ignorados no

\footnotetext{
${ }^{1}$ Doutoranda do Programa de Pós-Graduação em Arte e Cultura Visual da Universidade Federal de Goiás/GO FAV/UFG. Mestre em Artes Visuais, Bacharel e Licenciada em Desenho e Plástica - Artes Visuais, todos pela Universidade Federal de Santa Maria/RS. Membro do Grupo de Estudos e Pesquisas em Arte, Educação e Cultura (GEPAEC) e do Grupo de Pesquisa Cultura Visual e Educação (GPCVE). Bolsista REUNI/CAPES.
} 
tocante a relação imagem e espectador (binômio que também suscita a revisão/troca por outros termos que melhor se adéquem aos enfoques da cultura visual). Pode-se citar como um exemplo disto a compreensão da imagem como dispositivo evocativo da subjetividade do espectador, despertando o olhar carregado pelas particularidades, vivências, fragmentos identitários pertencentes ao indivíduo.

A subjetividade ganha espaço de relevância nas investigações acerca das visualidades como produtoras de sentidos, como potências para análise das relações do indivíduo em meio à sociedade na qual está inserido. Neste sentido, o contexto do espectador é compreendido como determinante em sua relação com a imagem, não sendo este um mero receptor, observador, mas compreendido também como produtor daquilo que vê (BREA, 2010), ao passo que as imagens são produzidas cada vez mais em razão de suas expectativas e/ou exigências.

A ampliação do campo de investigação para além das fronteiras do tradicionalmente acadêmico, abrindo espaço e compreendendo a pertinente e frutífera possibilidade de tomar como mote de análise aspectos e objetos pertencentes ao âmbito do cotidiano, reconfigura concepções quanto aos objetivos de uma pesquisa, bem como os intuitos herméticos e precisos da obtenção de dados conclusivos. Vislumbra-se assim, a possibilidade de respostas variadas e mutáveis em relação às circunstâncias em que se dão os fatos.

De acordo com Imanol Aguirre

(...) uma das conseqüências mais relevantes da aparição da cultura visual como campo de estudos é aquela que contribuiu para gerar um novo âmbito de ação e reflexão, acrescentando ao nascente interesse pelas questões de narratividade e significado, a atenção pelo visível e a visualidade como campo para ser observado e como perspectiva da qual observar.

Deste modo, os estudos da cultura visual, com sua ênfase na deriva cultural de tal regime de visualidade, respondem perfeitamente ao desmoronamento das grandes narrativas universalizantes, abrindo espaços para um estudo muito mais detalhado que dê conta das especificidades circunstanciais e contextuais de seu objeto de estudo. (2011, p.68)

Diante da complexidade do mundo e da consideração das subjetividades que produzem cada indivíduo, de cada contexto, a impossibilidade de obter respostas que possam dar conta de questões referentes às ações do sujeito social não se apresenta problemática. Esta impossibilidade sugere que ao invés de buscar respostas estanques, talvez fosse mais interessante observar os movimentos no entorno das relações e questões indivíduo/sociedade a fim de valorizar as singularidades, de compreender cada pessoa como parte determinante da sociedade da qual faz parte. 
Assim sendo, para o desenvolvimento do presente artigo parto da observação acerca das subjetividades dos sujeitos, estas amiúde condicionadas por relações de poder em que o tema gênero aparece em destaque, influenciando significativamente modos de ser/estar em sociedade. Alio a isto a concepção de que os objetos de investigação destes modos de atuação no âmbito social podem ser pensados a partir de motes oriundos do cotidiano. Penso a construção das reflexões deste texto a partir de um local a priori desconexo com as investigações científicas, mas que se configura como lugar profícuo para pensar minha subjetividade e construção identitária: meu caderno de receitas culinárias.

Pretendo aqui trazer considerações iniciais no tocante à investigação de práticas culinárias e de cadernos de receitas como locais e fazeres que podem evocar discussões acerca das relações de gênero construídas socialmente. A partir de tais reflexões, intenciono pensar de que modos tais questões referentes à construção de gênero e os discursos construídos acerca do tema, são determinantes na prática docente. Para tanto, busco desenvolver reflexões acerca de como as práticas culinárias e os cadernos de receitas, os elementos que os constituem, os modos de produção e os sujeitos envolvidos nestes processos, podem contribuir na investigação sobre a relação indivíduo/sociedade a partir desta produção.

Parto da observação de meu caderno de receitas culinárias como objeto de investigação de minha produção subjetiva, pensando que este não se constitui apenas de registros e modos de preparo de comidas, mas também abriga em suas páginas elementos de ordens variadas, que contam um pouco sobre minha história. Nas imagens, frases, objetos presentes em seu interior são observáveis fragmentos que sugerem construções das relações sociais e culturais, elementos que apresentam questões determinadas pelo contexto no qual me insiro.

Ao refletir sobre seu modo de construção, pautado a priori no intuito de subverter as características primordiais do objeto que inspirou sua criação - a saber, o caderno de receitas de minha mãe - observo as significativas questões de gênero imbricadas na produção de meu objeto de pesquisa, os discursos que fui construindo e que de algum modo foram se configurando na produção de meu caderno e de minha relação com a prática culinária. Discursos esses que não se encerram no ato de cozinhar e de seu registro no caderno, mas que invadem também minha prática docente influenciando e condicionando as abordagens no tocante à questão de gênero.

$\mathrm{Na}$ cozinha despontam as relações de gênero, de geração, a distribuição das atividades que traduzem uma relação de mundo, um espaço rico em relações sociais, fazendo com que a mesa se constitua, efetivamente, num ritual de comensalidade. A cozinha se reafirma, portanto, como um espelho 
da sociedade, um microcosmo da sociedade, uma imagem da sociedade, valores esses demonstrados pelos cadernos de receitas. (SANTOS, p.2, 2008)

Portanto, os elementos que constituem um caderno de receitas expandem-se dizendo respeito não apenas à questão do alimentar-se, do cozinhar, mas contam engendramentos sociais e culturais presentes por detrás destes atos do dia-a-dia. Disto, penso em como práticas cotidianas podem invadir e dizer de atividades desenvolvidas em outros setores de nossas vidas, tanto quanto podem dar pistas de como assumimos determinadas condutas, produzimos determinados discursos.

Tais questões não apenas sugerem a observação acerca de como vamos nos construindo, de fragmentos que vão sendo incorporados às nossas vivências, ao passo que dialogamos e interagimos com nosso contexto. Estes aspectos ampliam a possibilidade de pensar o conceito restrito e fechado do termo "receita", este passo-a-passo sugerido, que "secretamente" carrega consigo a inserção do "ingrediente a mais" colocado por cada cozinheiro(a), bem como da adaptação de receitas em razão das possibilidades oferecidas pelo local/contexto cultural de seu preparo.

De mesmo modo, percebo a construção de cada indivíduo mediante referências próprias do local e do período do qual faz parte, construindo suas concepções e ações em âmbito social determinadas por condutas pré-estabelecidas socioculturalmente, todavia atravessadas por inúmeros afetos, fatos, circunstâncias, que podem em um momento ou outro "modificar a receita original", sugerindo as relações de negociação que se dão no campo da cultura.

Nestes "desvios" de receita é possível perceber a determinante influência do universo de imagens, que acabam por sugerir combinações de sabores por vezes inusitados, sedutoramente apetitosos e permissivamente flexíveis à incorporação de ingredientes das ordens mais variadas. Incluo em mim ingredientes que desvirtuam preceitos de tradição e, ao passo que estas imagens sugerem personagens com as quais eu poderia me identificar e assumir (HALL, 2006), estas também acabam por gerar discursos outros que afetam não apenas as construções de universos imagéticos, mas também dos discursos em torno destes.

O caderno de receitas - objeto tradicionalmente feminino - construiu sua visualidade sob características de artefato construído por mulheres em meio a uma sociedade patriarcal. Nesta visualidade amiúde parecem observáveis, diante do imaginário social, elementos compreendidos como característicos do universo feminino, bem como uma finalidade voltada ao cuidado do lar, de marido e de filhos. Apesar da crescente produção de locais para compartilhamento de receitas através de meios tecnológicos, como blogs, a 
compreensão de um caderno material destinado ao registro de receitas ainda parece arraigado à antiga concepção de folhas amareladas, preenchidas por uma bela caligrafia e por elementos decorativos. Tal visualidade acaba por invocar concepções acerca do feminino que, embora na contemporaneidade se profira dotado de múltiplas possibilidades características em sua manifestação, desvela sob discursos ocultos o mantenimento de condutas pré-definidas para se construir mulher.

Sob essa perspectiva, evidencia-se a não passividade frente às visualidades e os discursos por elas sugeridos, mas a significativa relevância que esta possui na construção de identidades e subjetividades. Neste sentido indago-me sobre como é possível pensar as imagens que nos rodeiam, sem permitir que este olhar seja atravessado pela inevitável pujança dos aspectos que participam de nossas vivências. Se parece claro que elas nos constroem, também parece clara a incorporação de propostas que as compreendam como potências de construção e matéria primordial das relações socioculturais. E neste processo, parece pertinente atentar para os trânsitos entre o contexto de origem do indivíduo e os trajetos que se ramificam ao longo do seu percurso.

As pesquisas orientadas pela perspectiva da cultura visual buscam atender justamente a essa demanda, compreendendo a pertinência de estudos que partam da vida cotidiana, da significativa gama de imagens que transitam por ela e que acabam por produzir identidades, bem como gerar significados (TAVIN, 2009). Tal concepção aliada à pesquisa narrativa amplia a possibilidade de um estudo que parta das experiências vividas pelo pesquisador, compreendendo na presente investigação a possibilidade de abordar questões a priori pessoais, mas que podem contribuir para reflexões acerca dos debates sobre gênero.

Parto então deste mundo particular de imagens, que se constrói sob a forma de redes e que encontra nas páginas de um "mero" caderno de receitas um meio de organizar a experiência, refletir sobre minha subjetividade, sobretudo no que diz respeito à construção de gênero, expandindo a reflexão acerca de minha prática e construção docente - foco da pesquisa de doutorado atualmente desenvolvida no Programa de Pós Graduação em Arte e Cultura Visual/UFG.

\section{Pitadinhas de construções identitárias e gêneros}

A cultura das mulheres está para a cultura popular assim como a cultura popular está para o conjunto da cultura, de modo que é mais fácil dizer o que ela não é do que o que ela é. A cultura das mulheres não era a mesma que a dos seus maridos, pais, filhos, ou irmãos, pois, ainda que 
muitas coisas fossem partilhadas, também existiam muitas das quais as mulheres estavam excluídas. (BURKE, 1989, p.76)

Partindo desta afirmação de Peter Burke teço relações com a prática culinária e com caderno de receitas como tema e local que se inserem na cultura popular ao longo dos anos, contando por meio de receitas, de seu uso e intencionalidades, questões que perpassam pela discussão acerca do feminino, distinções entre classes socais, bem como acerca das tradições e costumes específicos de locais observados sob a perspectiva da alimentação e do ato de cozinhar.

Os cadernos de receitas culinárias relatam concepções distintas sobre os papeis masculino e feminino ao longo da história, o que é sugerido por meio de tradições passadas de uma mulher para outra. De acordo com Gilberto Freyre (1997), desde a segunda metade do século XIX até meados dos anos 70, os cadernos de receita constituíam-se como parte de um ritual feminino, a perpetuação de um conhecimento dentro de um grupo específico.

Destarte, é importante pensar a relação da alfabetização feminina em consonância com a produção de cadernos de receita. O que a priori era realizado por meio da oralidade, reconfigura-se a partir do acesso ao letramento. Todavia, a questão da utilização da escrita feminina tomando como base a criação de cadernos de receitas, só vem a reforçar os limites impostos à mulher e a distinção acerca da leitura e escrita que lhe era destinada.

Tais aspectos de registro de uma atividade cotidiana como um potencial investigativo de comportamentos e sistemas socioculturais foram fortemente ignorados pelo âmbito científico enquanto elementos relevantes para análise. Entretanto, sob a luz dos Estudos Culturais e da emergência dos Estudos do Cotidiano tais temas ganham a compreensão da riqueza de dados que podem prover para reflexão sobre certos aspectos da ação humana, esta demarcada inclusive pelas mais ordinárias atuações que desenvolve.

Em A invenção do cotidiano - Volume 2, um capítulo produzido por Luce Giard propõe-se justamente a abordar as inúmeras relações socioculturais articuladas na prática cotidiana da culinária. Em seus apontamentos, a atenção sobre a relação do feminino com a culinária conta sobre os silêncios que marcam a história das mulheres ao longo dos anos, bem como sobre o pouco reconhecimento acerca das funções exercidas por elas. Questões essas associadas ao pouco interesse dispensado aos fazeres do cotidiano como mote de estudos culturais.

Neste nível de invisibilidade social, neste grau de não reconhecimento cultural, coube há muito tempo e ainda cabe, como de direito, um lugar às mulheres, uma vez que, em geral, não se dá qualquer atenção às suas 
ocupações cotidianas: é preciso que "essas coisas" sejam bem feitas, portanto alguém tem que fazê-las; de preferência será uma mulher, outrora era uma "criada para todo o serviço". Esta própria designação revela exatamente o status e a função. Trabalhos que visivelmente nunca acabam, jamais suscetíveis de receber um arremate final: a manutenção dos bens do lar e a conservação da vida da família parecem extrapolar o campo de uma produtividade digna de ser levada em conta. Só quando faltam é que chamam a atenção, mas neste caso é ainda de reprovação que se trata. (GIARD, 1996, p. 217)

Estas reflexões, quando voltadas para o âmbito da culinária, vêm a reforçar a noção de que este aponta para uma história de um grupo que por muito esteve à margem. As relações de poder entre os sexos que permeiam as atividades exercidas por homens e mulheres contam a construção de uma economia política do sexo, como propõe Gayle Rubin (1993), que erigida sob uma concepção patriarcal heterossexista atribui a cada sexo um tipo específico de atividade determinados em razão de seu aspecto biológico. Tal projeto a princípio foi construído com intuito social, entretanto atualmente é meramente reproduzido como modelo de conduta. Rubin ainda acrescenta: "o mesmo sistema social que oprime as mulheres nas suas relações de troca, oprime todo mundo pela sua insistência numa divisão rígida de personalidade." (1993, p.12).

Estas personalidades, a que se refere a autora, podem ser percebidas como construídas imageticamente em cada âmbito social. São esperadas condutas, são determinadas características e posturas a serem assumidas por homens e mulheres. E nos objetos destinados ao uso para cada um dos sexos, as marcas das construções de gênero em épocas e culturas específicas. Assim, pode-se pensar as inúmeras questões que permeiam, por exemplo, a prática de construção de um caderno de receitas e que não adentram de modo literal suas páginas. E neste sentido reporto-me ao caderno de receitas de minha mãe, que guarda em seu interior não apenas receitas culinárias, mas apresenta por meio de escritas e recortes variados, também "receitas" de ser. E nisto penso o termo "receita" envolto por inúmeros aspectos possíveis como: projeção, insegurança, domínio, alteridade.

As páginas de seu caderno ganhavam aos poucos status de diário, não apenas relatando acontecimentos, registros de práticas de uma dona de casa que cozinhava na grande maioria das vezes o trivial, mas que selecionava receitas que continham ingredientes os mais variados, aos quais ela dificilmente investiria o valor necessário para sua compra. Não o fazia por não possuir a quantia de dinheiro necessária para estas compras, mas sim por ter passado por um começo de casamento marcado pela escassez financeira, além de ter sido ensinada a compreender que a renda do marido era mérito apenas dele, isto é, direito exclusivo do chefe da família. Seu caderno conta um modo de ser mulher carregado por aspectos culturais e políticos de uma geração. E indica ainda, pelos 
elementos que abriga em suas páginas, outras mulheres que só se sentiam seguras para manifestarem-se naquele local/objeto.

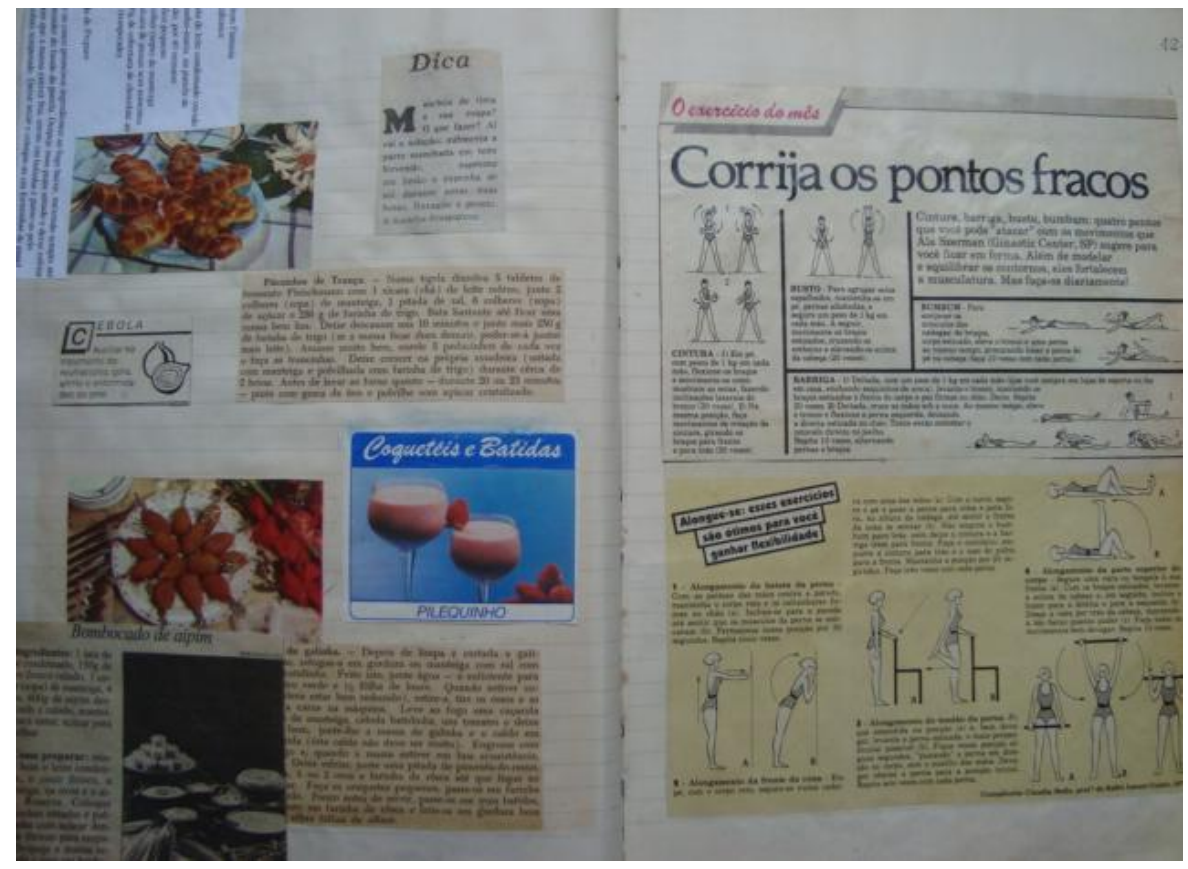

Fig. 1 - Imagem de páginas do caderno de receitas da minha mãe

Estes apontamentos reforçam as questões mencionadas anteriormente e, ainda, visam justificar meu interesse pelo tema, posto que toca aspectos da reflexão sobre gênero assunto que há algum tempo motiva-me enquanto pesquisadora - possibilitando uma pesquisa que parta de minhas vivências. Para tanto, na presente pesquisa de doutorado me utilizo não apenas dos possíveis temas que observo no caderno de receitas de minha mãe, mas, sobretudo do modo como este impulsionou a construção do meu caderno. E deste modo, transito também pelas questões que perpassam a construção de meu gênero em meio e, sob o regime, de um contexto sociocultural específico.

Os elementos que me despertam interesse e que acabam adentrando as páginas do caderno de receitas são efetivamente atravessados pelos sistemas de imagens que permeiam meu contexto, bem como pelas referências culturais de minha época. 


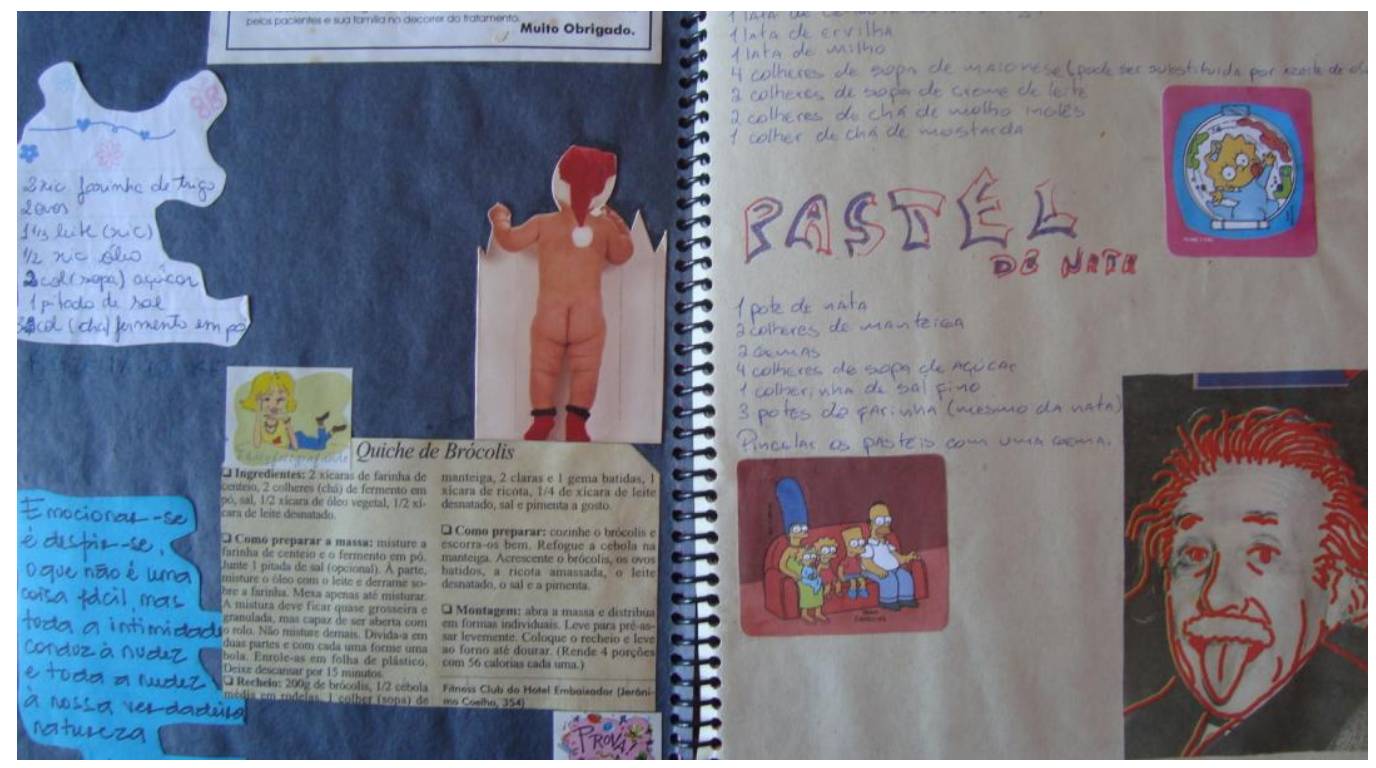

Fig. 2 - Imagem de páginas de meu caderno de receitas

Estes elementos são significativamente escolhidos em razão das situações que vivencio, em que me são sugeridas a todo o momento identidades que também se constituem nas mais corriqueiras ações cotidianas e que dialogam, chocam-se e desdobram-se com minha subjetividade. Deste modo, pensar a ação das esferas culturais na formação e conformação do sujeito parece necessário para desenvolver uma reflexão acerca de como uma prática cotidiana é permeada por agências de construção identitária.

O caderno de receitas marcado pela inserção de conteúdos que remetem ao cuidado do lar, motivado pela descoberta de pratos que possam ser realizados para a família, reconfigura-se não só pelos possíveis formatos de lar e família que emergem na contemporaneidade, bem pelos interesses outros que podem fazer parte das vidas femininas atuais. Com isso não pretendo dizer que não existam mais locais destinados a abrigar receitas que lembrem produções de tempos anteriores, contudo reforço que este objeto que carrega consigo o peso quase inato de abrigar tradições femininas, também sofre transformações em razão das mudanças nas concepções de construção do referido gênero.

Talvez seja hora de assumirmos explicitamente que nossas propostas sobre as "mulheres" não são baseadas numa realidade dada qualquer, mas que elas surgem de nossos lugares na história e na cultura; são atos políticos que refletem os contextos dos quais nós emergimos e os futuros que gostaríamos de ver. (Nicholson, 2000, p.30)

Minha relação com a cozinha, bem como a construção de meu caderno não é pautada pelo cuidado com a família, mas sim pelo desejo pessoal de descobertas, experiências, aprendizagens e interação com outras pessoas. A prática culinária e a criação do caderno, mesmo fugindo aos preceitos erigidos tradicionalmente no entorno destes, 
permitem dizer-me mulher de acordo com aquilo que me afeta culturalmente. Nisto estão presentes tanto as visualidades que buscam definir os gêneros, bem como os possíveis trânsitos entre estes e que se evidenciam cada vez mais.

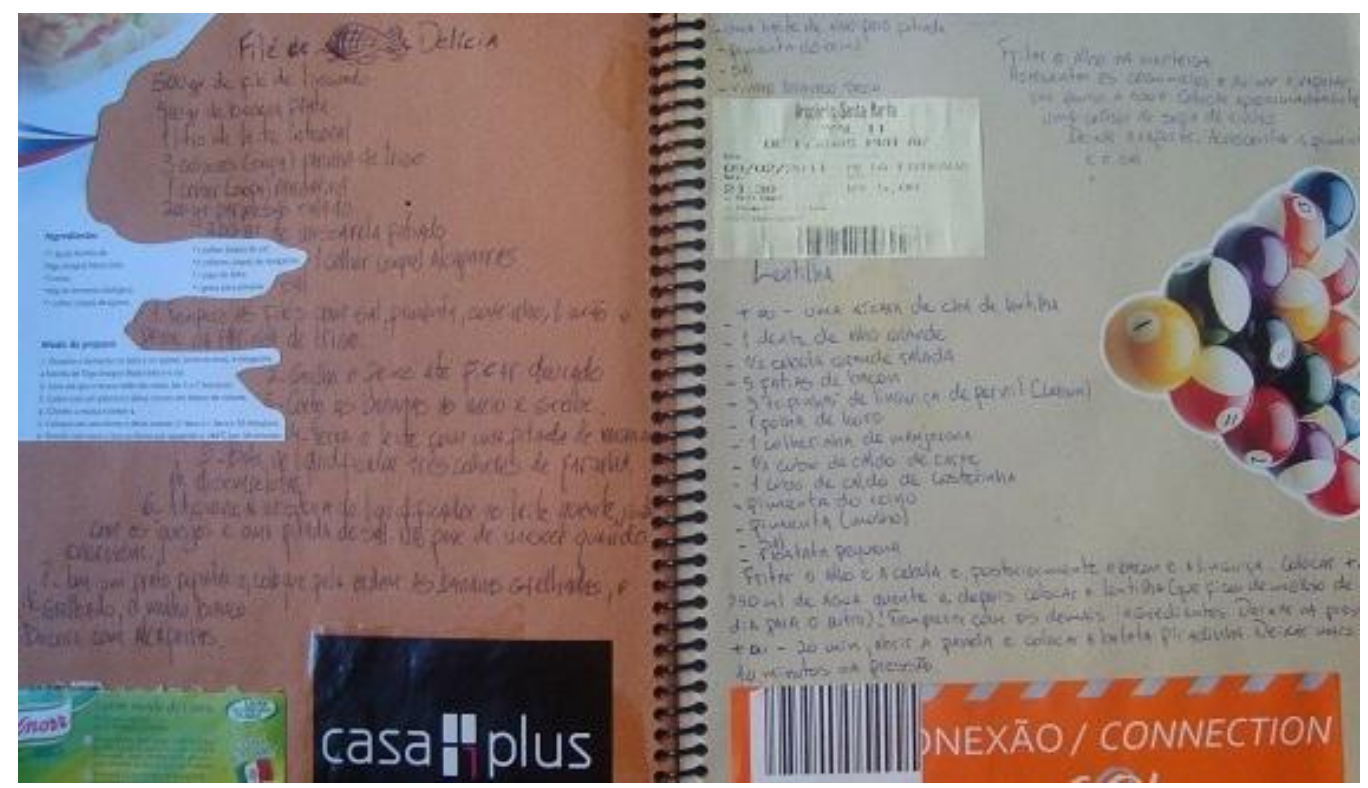

Fig. 3 - Imagem de páginas de meu caderno de receitas

Neste sentido, se me proponho a refletir sobre como as imagens me constituem, é ímpar pensar, como menciona Certeau (1994), que estas centram-se também nos modos de atuar, nas práticas cotidianas que são atravessadas por estes universos imagéticos, pelas visualidades do dia-a-dia. E se estas práticas cotidianas são permeadas por imagens que atuam nos modos de vida, nas subjetividades, efetivamente agem também sobre a constituição do indivíduo nos inúmeros sujeitos em que este se desdobra no âmbito social. E por esta razão, reporto-me à construção docente.

Retomo então aspectos abordados na elaboração da pesquisa de doutorado, os quais dizem respeito aos enfoques metodológicos e que, ao pautarem-se nas investigações narrativas, encontram subsídios para investigação de minha trajetória enquanto docente, por meio da organização particular de experiências pessoais. Entretanto, compreendendo que tais experiências ocorrem de modo relacional, influenciadas determinantemente pelas redes de interação com demais sujeitos e contextos. Martins e Tourinho inferem que:

(...) ao falarmos de experiência estamos nos referindo a vivências que são ao mesmo tempo pessoais e sociais. As pessoas necessitam ser identificadas e tratadas como indivíduos, mas esta condição (pessoal), não as priva de uma vida social. Como seres humanos construímos nossas experiências individuais de modo relacional, ou seja, sempre em contexto, sempre no mundo social. (MARTINS e TOURINHO, 2009, p.6-7) 
Aos poucos meu caderno vai ganhando novos recortes e nestes estão marcas daquilo que me acontece enquanto aprofundo questões que dizem respeito a minha formação no campo das artes visuais e agora também da cultura visual. Ao passo que vou incluindo novas receitas, novos sabores, vou introduzindo também elementos outros acerca de minha formação que vão ganhando corpo nas discussões e redes de sociabilidade. Também, ao passo que vou atuando como docente, percebo nas identidades que se desenvolvem no âmbito escolar, as construções e performatividades dos gêneros que se evidenciam nas 'simples' ações cotidianas.

A cultura do cotidiano é um espaço que informa o espetáculo de gênero e sexualidade em nossa cultura e a juventude faz uso da bricolagem no cotidiano como uma tentativa autônoma de construir e reapresentar sua percepção dessas performances culturais. Portanto, uma prática de educação da cultura visual que destaque as representações culturais do cotidiano, de gênero e sexualidade é uma experiência pedagógica significativa porque fornece uma miríade de oportunidades para cingir e adotar uma visão diversa da cultura, que não somente resiste acriticamente às representações visuais, mas incentiva a visão crítica como uma prática que desenvolva a imaginação, a consciência social e um sentido de justiça. (DIAS, 2011, p. 83 - 86)

Ao pensar as relações de gênero, que há muito me são caras, e que suscitaram reflexões a partir de minha relação com a culinária e a produção de um caderno de receitas, inevitavelmente tais ponderações acabam determinando meu modo de ser docente e os discursos que produzo sobre as construções de gênero. Direcionamentos que podem parecem banais, como temas e perspectivas de fala a serem abordadas em uma aula, acabam sendo invariavelmente afetados pelos discursos que fui construindo em minhas vivências e ainda, que me foi sugerido pelo contexto sociocultural do qual faço parte.

A partir de Loponte (2007) penso como a prática docente é determinada por inúmeros fatores que perrmeiam nosso cotidiano, encharcando-nos com possibilidades variadas de ser docente. No trabalho que realizou com grupos de professoras de arte da Universidade de Santa Cruz/RS e que deu origem a sua tese, Luciana investigou o processo de formação continuada destas professoras por meio das escritas produzidas por elas. Nisto, observa o professor como uma "esponja" (como cita uma das professoras de sua pesquisa) que absorve inúmeras coisas que acontecem no entorno da prática profissional e que não se dissociam de seus modos de atuação em sala de aula, pelo contrário, somam-se às experiências. (LOPONTE, 2007, p. 238)

Nos fatores que agem neste âmbito da prática docente estão presentes livros, autores, bem como referências trazidas por demais pessoas de nosso convívio, que acabam produzindo sistemas de conhecimento e interesse. Processos de interação que vão das mais variadas formas - e aqui retomo a razão de meu olhar para o ato de cozinhar - 
compreendendo esta como uma atividade que há muito estabelece conexões com a reflexão acerca da docência e com o gênero.

As pensar as imagens presentes no meu caderno de receitas e as visualidades que percorrem meu ensinamento acerca do conceito de feminino, observando as relações políticas e de poder presentes nesta conceituação, direciono minha atenção à abordagem (ou a não-abordagem) do tema em âmbito escolar. Compreendendo que "o conhecimento é socialmente construído e relacionado intrinsecamente ao poder", como afirma Dias (2011, p. 62), resultam dessas reflexões sobre construções de gênero em meio às práticas cotidianas e sob a perspectiva da cultura visual, posturas em minha atuação docente que se voltam à problematização das relações de poder por detrás dos discursos sugeridos pelas visualidades cotidianas.

Para que tal proposta pedagógica se configure, creio ser indispensável percorrer os caminhos que me traçaram dentro do gênero feminino, sobretudo atentando para as inúmeras variáveis possíveis para este e sugeridas pelas transformações que vivencio em meu contexto. Assim, observar a relação que estabeleço com a culinária e com o caderno de receitas, as motivações que impulsionaram e nortearam esse interesse e que dizem respeito às minhas reflexões sobre gênero, parece-me imprescindível para promover discussões sobre como tais questões estão presentes no dia-a-dia e como somos atuantes em seus modos de estruturação.

\section{Finalizando o prato}

Meu interesse pela cozinha não se configura apenas por meio do desejo de descobrir novos sabores, técnicas e combinações. É um interesse intrinsecamente voltado ao ato de reunir-me com demais pessoas, por vezes motivado pela vontade de experimentar novos pratos, em outras pela vontade de pensar conjuntamente a respeito de determinado assunto. Entretanto, ambas as questões estão interligadas, sendo deste modo inevitável que os assuntos confluam e que cada vez mais se imbriquem. Ou ainda, que permitam a emergência de questões que, em alguns momentos não se pronunciam em ocasiões de formalidade acadêmica.

Os fragmentos que adentram o caderno de receitas são permeados pelos fatos que me acontecem cotidianamente e que são produzidos também sob a forma de visualidades. Neste processo, dialogam receitas que contam experiências, tempos distintos, aspectos das ordens mais variadas que determinam tanto a realização de um prato, como a 
urgência de um encontro de "produção intelectual não formal". ${ }^{2}$ A cultura visual me proporciona tanto a possibilidade de investigar como tais experiências visuais atuam em minha construção identitária e subjetiva, como também de perceber de que modos também atuo na produção de visualidades carregadas de discursos político-identitários.

Reflito sobre como ocorrem os processos de minha construção identitária docente, não apenas em sala de aula e frente a um professor, mas, sobretudo nas trocas que faço com colegas, amigos, o porteiro do prédio, a moça da fruteira... e também, por meio de todas as coisas que "cato" e que colo em meu caderno de receitas como evidências do vivido, do conhecido e saboreado, ou daquilo que ainda está por ser descoberto. E nisto, amiúde retornam questões que evocam relações de gênero no entorno da prática culinária, na produção deste caderno de receitas e que inevitavelmente atravessam minha construção enquanto professora.

Assim, anoto as receitas dos ingredientes de que me utilizei para construir-me até então, acrescento ingredientes que vou descobrindo, bem como recorro aos que me são "base segura". Construo-me enquanto discente, professora, cozinheira, sem vestir identidades fixas no momento de atuação em cada um destes âmbitos, todas se atravessam. E, é neste universo de imagens e receitas que recolho, nas questões de gênero que delas emergem e com os quais estabeleço diálogos, que tenho vislumbrado possibilidades de problematizar as questões de minha prática docente embasada pela perspectiva da cultura visual.

\section{Referências:}

AGUIRRE, Imanol. Cultura visual, política da estética e educação emancipadora. In.: MARTINS, Raimundo; TOURINHO, Irene (orgs.). Como e por que pensamos a educação da cultura visual. Santa Maria: Ed. da UFSM, 2011.

BREA, José Luis. Recepción 2.0. In.: BREA, José Luis. Las Tres Eras de la Imagen Imagen-materia, film, e-image. Madrid: Akal, 2010.

BURKE, Peter. Cultura Popular na Idade Moderna. São Paulo Companhia das Letras, 1989.

CERTEAU, Michel. A Invenção do cotidiano: 1. Artes de fazer. Petrópolis: Ed. Vozes, 1994.

\footnotetext{
${ }^{2}$ Modo como me refiro a estes momentos em que discuto com amigos alguns temas de nossas vidas profissionais, sobretudo a respeito de questões acadêmicas, descontraídos pela informalidade propiciada pelo concomitante momento de preparo de um prato e de seu degustar.
} 
GIARD, Luce; MAYOL, Pierre. A invenção do cotidiano: 2, morar,cozinhar. Petrópolis: Artes de Fazer, 1996.

DIAS, Belidson. O I/Mundo da Educação em Cultura Visual. Brasília: Editora da PósGraduação em Arte da Universidade de Brasília, 2011.

FREYRE, Gilberto. Açúcar. São Paulo: Companhia das Letras, 1997.

HALL, Stuart. A identidade cultural na pós-modernidade. Rio de Janeiro: DP\&A, 2006.

LOPONTE, Luciana. Arte da docência em arte: desafios contemporâneos. In.: OLIVEIRA, Marilda (orgs.). Arte, Educação e Cultura. Santa Maria: Ed. da UFSM, 2007.

MARTINS, Raimundo; TOURINHO, Irene. Pesquisa narrativa: concepções, práticas e indagações. In: Anais do II Congresso de Educação, Arte e Cultura - CEAC. Santa Maria: 2009.

NICHOLSON, Linda. Interpretando o gênero. Revista Estudios Feministas, CFH/CCE/UFSC, Santa Catarina, vol. 8, nº 2, 2000, pág. 8-41.

RUBIN, Gayle. 0 tráfico de mulheres: notas sobre a economia política do sexo. Recife: S.O.S Corpo, 1993.

SANTOS, Carlos Roberto Antunes. Os pecados e prazeres da gula - os cadernos de receitas como fontes históricas. Disponível em <http:// www.poshistoria.ufpr.br/fonteshist/Carlos\%20Antunes.pdf>. Acesso em 08 de dezembro e 2011.

TAVIN, Kevin. Contextualizando visualidades no cotidiano: problemas e possibilidades do ensino da cultura visual. In: MARTINS, Raimundo; TOURINHO, Irene (Orgs.). Educação da cultura visual: narrativas de ensino e pesquisa. Santa Maria: Editora da UFSM, 2009. 